\title{
Clinical Outcomes of Four-Corner Arthrodesis Using Circular Plate for Scaphoid Nonunion Advanced Collapse (SNAC)
}

\author{
Ayman Mustafa ${ }^{1}$, Mutasem Aldhoon $^{2 *}$, Ghandi Almanasir ${ }^{2}$, Saeb Almesterihi ${ }^{2}$ and Ahmad Al-Zoubi ${ }^{2}$ \\ ${ }^{1}$ Chief of hand and Upper Limb Surgery, Orthopedic Department, King Hussein Medical Center, Jordan \\ ${ }^{2}$ Department of Orthopedics, Royal Medical Services, Amman, Jordan
}

Submission: May 16, 2021; Published: May 26, 2021

*Corresponding author: Mutasem Aldhoon, MD, Pediatric Orthopedic Surgeon, Queen Rania Hospital for Children, King Abdullah II Street, Amman, Jordan

\begin{abstract}
Objectives: Scaphoidectomy and four-corner arthrodesis (FCA) using a circular plate is becoming a common surgical option as a salvage procedure for Scaphoid Nonunion Advanced Collapse (SNAC). In this article we report our experience at Royal Medical Services with Scaphoidectomy and four corners arthrodesis using a circular plate fixation and autogenous bone grafting showing our surgical technique, outcome and complications.
\end{abstract}

Methods: A retrospective review of all patients who underwent FCA with circular plate fixation between February 2014 to February 2019 at Royal Medical Services. Patients were called and asked to come back to our clinic for clinical and radiological evaluation. 26 patients with a mean age of 34 years (range, 24-56 years) at the time of surgery were evaluated for range of motion (ROM) using goniometer, for grip strength using a dynamometer and for carpal fusion based on the most recent postoperative wrist $\mathrm{x}$ ray.

Results: 26 procedures (26 patients) were clinically and radiologically evaluated. Range of motion averaged $52.9 \%$ compared to the contralateral wrist (average flexion $68.3^{\circ}$; average extension $30.7^{\circ}$; average radial deviation, $58.1^{\circ}$; average ulnar deviation, $54.5^{\circ}$ ). Grip strength averaged $34.9 \%$ of the opposite side. Radiological evaluation showed that 12 cases progressed to Full fusion (46.1\%), partial but solid fusion was present in 12 cases (46.1\%), while non-union was present in two cases (7.6 \%). Three patients (11.5\%) underwent additional operations (two for hardware removal and one for tendon exploration).

Conclusion: We found that FCA with circular plate yielded reasonable results, ensures fusion, and is a good alternative to traditional implants like K-wires, Herbert screws, or staples.

Type of study/level of evidence: Therapeutic IV.

Keywords: SNAC wrist; Four-corner arthrodesis; Circular plate

\section{Introduction}

Scaphoidectomy and four-corner arthrodesis (FCA) is a salvage procedure used for treatment of scaphoid nonunion advanced collapse (SNAC). This procedure was first described by Watson and Ballet in the 1980s and demonstrated reliable pain relief while preserving a functional wrist range of motion and grip strength [1-4]. Fixation methods for this procedure include K-wires, staples, headless compression screws and recently, circular plates (DCPs) were developed and introduced in 1999 [5]. Circular plate would provide pain relief, improved function, and a higher union rate compared to existing data of other Fixation methods [5,6]. At our institution, Scaphoidectomy and fourcorner arthrodesis (FCA) has been routinely performed using different fixation methods since 2008. However, the circular plate was predominantly used since 2014 . The purpose of this study is to analyze the outcome of using circular plate as a method of fixation in this procedure, specifically regarding residual range of motion (ROM) and grip strength as well as to assess fusion rate in this patient group.

\section{Materials and Methods}

\section{Patient selection}

A retrospective review was performed for all patients who underwent Scaphoidectomy and four corner arthrodesis using 


\section{Orthopedics and Rheumatology Open Access Journal (OROAJ)}

circular plate between February 2014 to February 2019 in Royal Medical Services by three different hand and upper limb surgeons. Patients were Included in the study if they were treated using a circular plate for SNAC wrist. Patients were excluded from the study if they underwent arthrodesis using any other implant. A total of 26 surgeries on 26 patients were identified that met the study criteria and were considered for inclusion. Surgical indication was SNAC wrist in all patients. The mean age of patients was 34 years. All were men and the Right wrist was involved in 14 patients while Left wrist was involved in 12 patients. 16 injuries were dominant side. The minimum follow-up was 18 months (mean, 28.2 months; range, 18-56 months). The demographic data are listed in Table 1.

Table 1: Details of patients treated with four corner arthrodesis.

\begin{tabular}{|c|c|c|c|c|}
\hline Case & Age (Y) & Sex & Side Involved & Dominant Side \\
\hline 1 & 38 & Male & Left & Right \\
\hline 2 & 30 & Male & Right & Right \\
\hline 3 & 33 & Male & Right & Right \\
\hline 4 & 34 & Male & Right & Right \\
\hline 5 & 31 & Male & Left & Right \\
\hline 6 & 27 & Male & Left & Left \\
\hline 7 & 34 & Male & Left & Right \\
\hline 8 & 27 & Male & Right & Right \\
\hline 9 & 34 & Male & Left & Right \\
\hline 10 & 38 & Male & Right & Right \\
\hline 11 & 33 & Male & Right & Right \\
\hline 12 & 56 & Male & Right & Right \\
\hline 13 & 24 & Male & Left & Right \\
\hline 14 & 38 & Male & Right & Right \\
\hline 15 & 38 & Male & Right & Left \\
\hline 16 & 30 & Male & Right & Right \\
\hline 17 & 29 & Male & Left & Right \\
\hline 18 & 35 & Male & Left & Right \\
\hline 19 & 37 & Male & Left & Left \\
\hline 20 & 44 & Male & Right & Right \\
\hline 21 & 29 & Male & Left & Right \\
\hline 22 & 29 & Male & Right & Right \\
\hline 23 & 37 & Male & Right & Right \\
\hline 24 & 33 & Male & Right & Right \\
\hline 25 & 37 & Male & Left & Left \\
\hline 26 & 29 & Male & Left & Right \\
\hline
\end{tabular}

\section{Radiological Assessment}

Radiological evaluation of carpal fusion status was based on the most recent postoperative poster anterior (PA) and lateral wrist $\mathrm{x}$ rays (Figure 1). fusion status was determined by a fellowship-trained hand and upper limb surgeon at our department. Full fusion was determined by the presence of bony consolidation across the intercarpal joints and absence of visible joint lines between all the four bones (lunate, capitate, hamate and triquetrum); whereas partial but solid fusion was defined as the union of the lunate and capitate. These definitions were used because successful clinical results depend on fusion of lunate and capitate, whereas incorporation of either hamate or triquetrum, in and of themselves, are not required for long-term stability of the carpus [2,7-9]. Non-union is defined as persistent visible joint lines between lunate and capitate. Postoperative $\mathrm{x}$ rays were also analyzed for any evidence of metallic failure or dorsal impingement. Range of Motion (ROM) and Grip Strength Final ROM measurements were obtained for all patients using goniometer. ROM $52.9 \%$ of the opposite side (average flexion, $68.3^{\circ}$; average extension, $30.7^{\circ}$; average radial deviation, $58.1^{\circ}$; average ulnar deviation, $54.5^{\circ}$ ). The grip strength was also obtained for all patients using dynamometer. The average grip strength was 13.5 $\mathrm{kg}$ which was an average of $34.9 \%$ of the opposite side. 


\section{Orthopedics and Rheumatology Open Access Journal (OROAJ)}

\section{Surgical Technique}

We performed the surgery through a dorsal midline skin incision in line with the third metacarpal bone. Sharp soft tissue dissection was carried down to the wrist extensor retinaculum. The third compartment with the extensor policies longus (EPL) was released and transposed. The fourth compartment opened, and its tendons were retracted to the ulnar side, in addition to posterior interosseus nerve neurectomy. The capsule was opened with a radially based flap. Next, the whole scaphoid was excised, and a high-quality cancellous bone graft was harvested from distal radius and scaphoid bone (Figures $2 \& 3$ ).

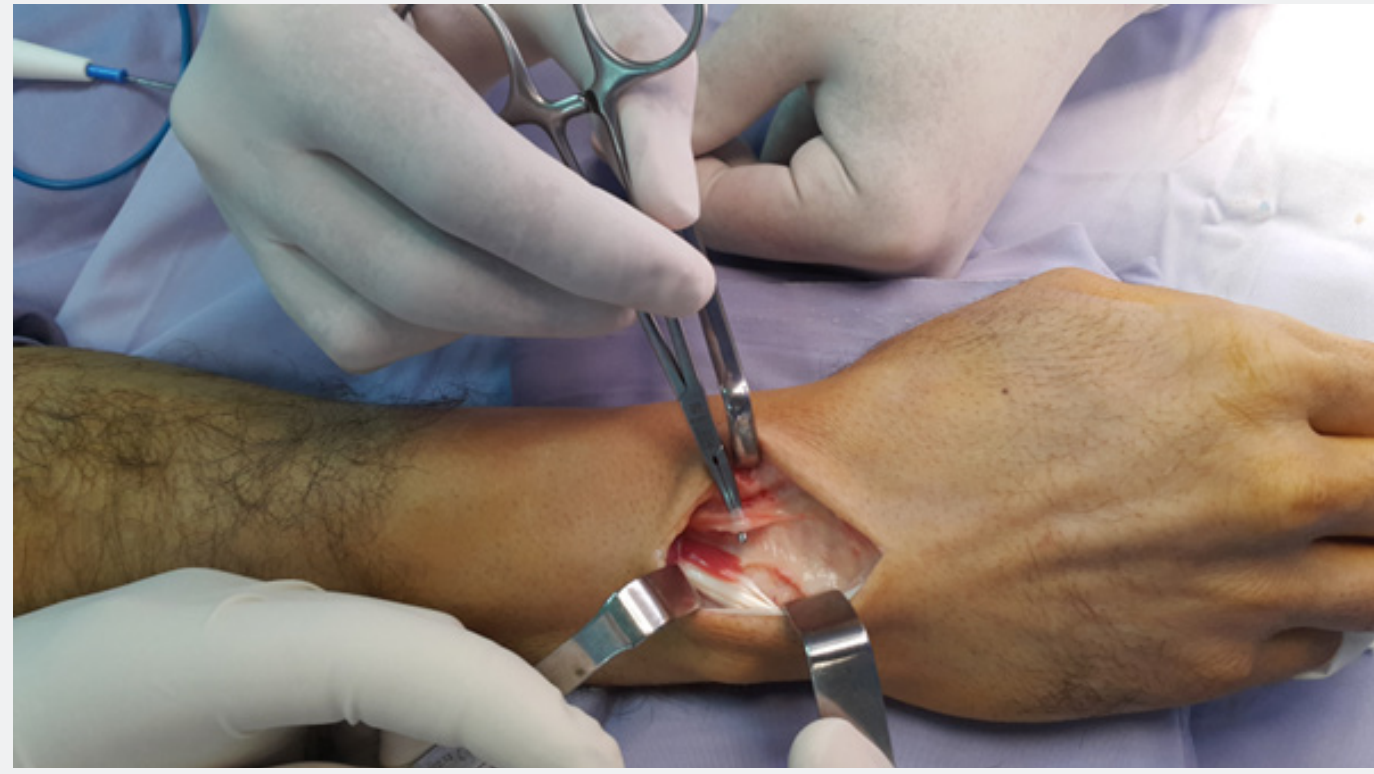

Figure 1: The PIN is identified at the floor of 4 th extensor compartment. At least $2 \mathrm{~cm}$ of the nerve should be excised to achieve proper PIN neurectomy.

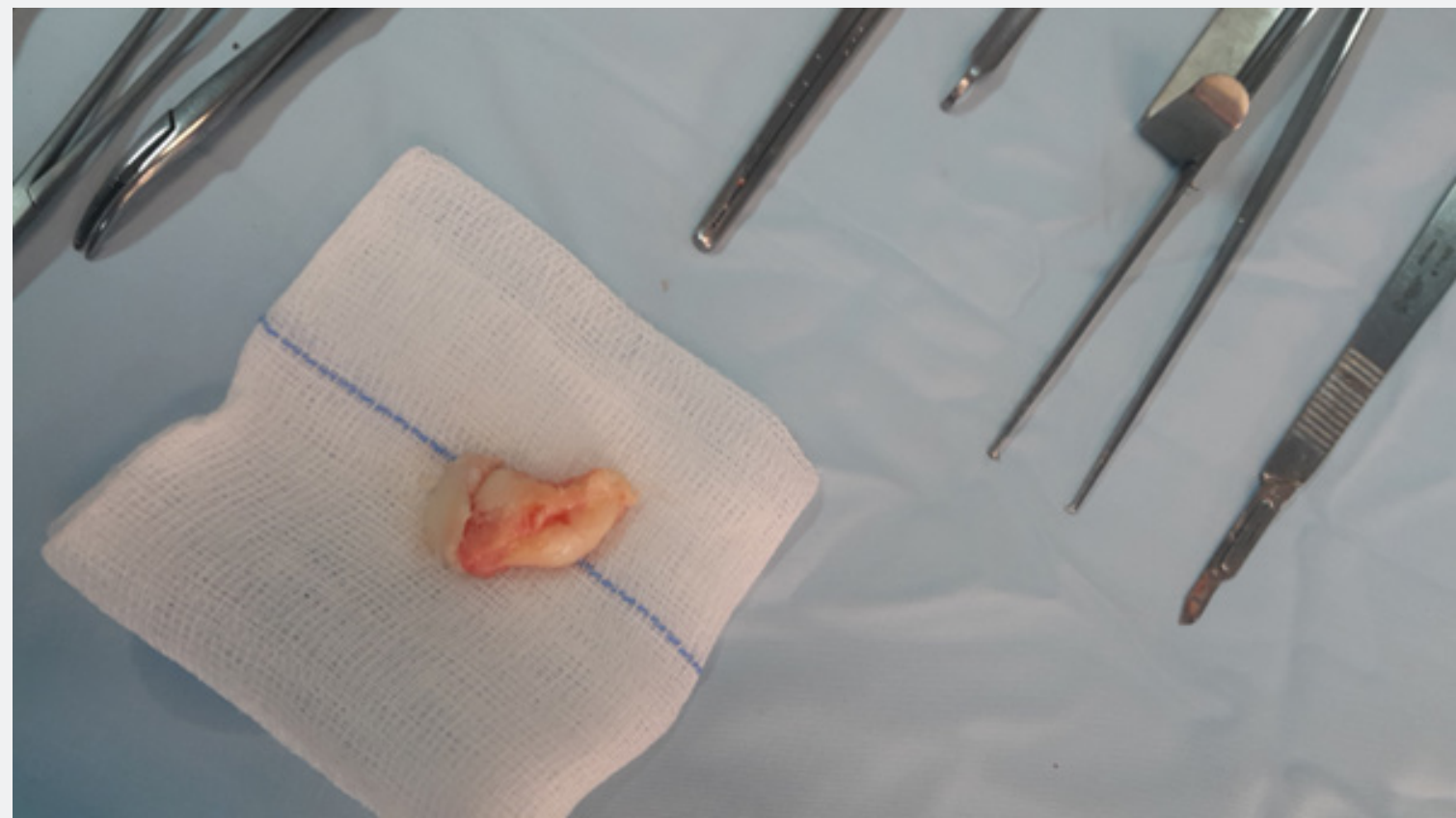

Figure 2: The whole scaphoid has been excised as one piece. Piecemeal excision can be done if excision as a single piece is technically difficult. 


\section{Orthopedics and Rheumatology Open Access Journal (OROAJ)}

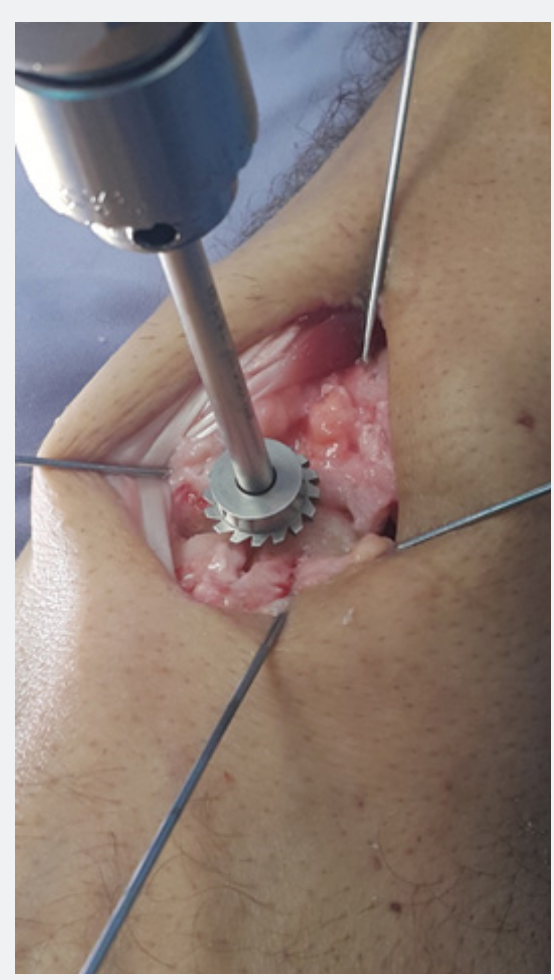

Figure 3A: The power rasp is centered over the four bones. Reaming should continue until the rasp is seated below the dorsal lip of the lunate to prevent postoperative impingement.

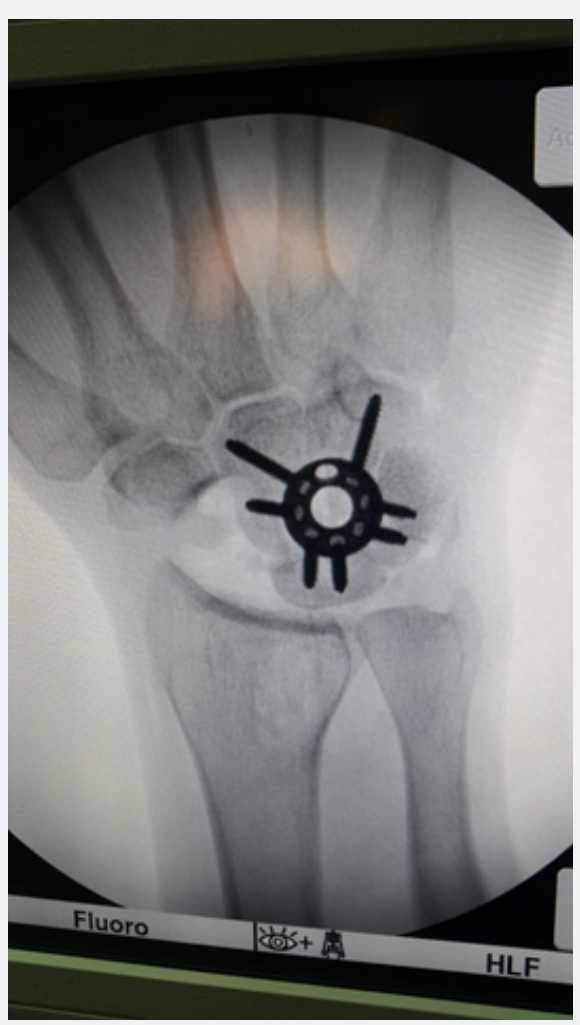

Figure 3B: Intraoperative $\mathrm{x}$-ray is used to confirm carpal bones alignment, circular plate position and screws length. 
A fine bone nibbler was used to denude all articulations down to bleeding cancellous bone of the capitate, lunate, triquetrum and hamate. The four corners of the bones were fixed provisionally with K-wires. The circular plate rasp was centered on the fourcorner area, and reaming was started until the rasp was seated below the dorsal tip of the lunate. Any debris were removed with small curette. The bone graft was packed between the bones. An appropriate-size circular plate was placed such that two screws could be placed into each of the 4 bones when possible. A $1.5-\mathrm{mm}$ drill bit was used, followed by either $2.4-\mathrm{mm}$ screws or $2.8-\mathrm{mm}$ screws depending on quality of bones. Screws were tightened progressively in a radial order, to maximum compression. Intraoperative $\mathrm{x}$-ray was used to confirm carpal bones alignment, circular plate position and screws length. More care was required for the triquetral screws, to make sure they do not penetrate the piso-triquetral joint. The center of the circular plate and the surrounding area were filled-up with bone graft. The capsule, retinaculum, and the skin were closed, respectively. The wrist was immobilized for 6 weeks postoperatively.

\section{Results}

The mean follow-up period was 28.2 months (range 18-56 months) Table 2. Full fusion was achieved in 12 patients at a mean time of 26 months (range 19-56 months) postoperatively. Another 12 patients (46.1\%) had a persistent visible line in triquetral-hamate joint; however, the fusion mass was stable (partial but solid fusion). Two cases (7.6\%) ended with nonunion. Two patients $(7.6 \%)$ had dorsal pate impingement that necessitated plate removal. Another patient (3.8\%) had weak ring finger extension and underwent surgery for tendon exploration and repair. There were no postoperative infections. Wrist flexion averaged $46.3^{\circ}$ (range, $27^{\circ}-65^{\circ}$ ), extension averaged $19.5^{\circ}$ (range, $0^{\circ}-34^{\circ}$ ), average radial deviation, $17.5^{\circ}$ (range $5^{\circ}-28^{\circ}$ ); average ulnar deviation $23^{\circ}$ (range, $15^{\circ}-32^{\circ}$ ). ROM of the surgically treated wrist was $52.8 \%$ that of the opposite normal wrist. Maximum grip strength of the surgically treated wrist averaged $13.5 \mathrm{~kg}$ which is $34.9 \%$ that of the opposite normal wrist (range, 11\%-61.9\%)

Table 2: Results of patients treated with four corner arthrodesis using circular plate.

\begin{tabular}{|c|c|c|c|c|c|c|c|c|c|c|c|c|}
\hline \multirow{3}{*}{ Case } & \multirow{3}{*}{$\begin{array}{c}\text { Fol- } \\
\text { low-up, } \\
\text { mo }\end{array}$} & \multirow{3}{*}{$\begin{array}{c}\begin{array}{c}\text { Grip } \\
\text { Strength } \\
\text { kg }\end{array} \\
\\
\begin{array}{c}\text { Op. } \\
\text { side }\end{array}\end{array}$} & \multicolumn{9}{|c|}{ Range of Movement, deg } & \multirow{3}{*}{ Fusion status } \\
\hline & & & \multicolumn{2}{|c|}{ Flexion } & \multicolumn{2}{|c|}{ Extension } & \multicolumn{2}{|c|}{$\begin{array}{c}\text { Radial Devia- } \\
\text { tion }\end{array}$} & \multicolumn{2}{|c|}{ Ulnar deviation } & \multirow[b]{2}{*}{$\begin{array}{l}\text { Nor } \\
\text { side }\end{array}$} & \\
\hline & & & $\begin{array}{l}\text { Nor } \\
\text { side }\end{array}$ & $\begin{array}{l}\text { Op. } \\
\text { side }\end{array}$ & $\begin{array}{l}\text { Nor } \\
\text { side }\end{array}$ & $\begin{array}{l}\text { Op. } \\
\text { side }\end{array}$ & $\begin{array}{l}\text { Nor } \\
\text { side }\end{array}$ & $\begin{array}{l}\text { Op. } \\
\text { side }\end{array}$ & $\begin{array}{l}\text { Nor } \\
\text { side }\end{array}$ & $\begin{array}{l}\text { Op. } \\
\text { side }\end{array}$ & & \\
\hline & 22 & 8 & 38 & 40 & 70 & 30 & 70 & 18 & 30 & 20 & 48 & Full Fusion \\
\hline & 18 & 12 & 32 & 28 & 54 & 30 & 70 & 20 & 29 & 22 & 44 & Full Fusion \\
\hline & 36 & 14 & 38 & 55 & 78 & 0 & 70 & 18 & 25 & 25 & 48 & Partial Fusion \\
\hline & 20 & 14 & 42 & 50 & 82 & 0 & 68 & 10 & 30 & 28 & 51 & Partial Fusion \\
\hline & 44 & 6 & 48 & 50 & 70 & 10 & 60 & 12 & 22 & 28 & 43 & No Fusion \\
\hline & 22 & 16 & 31 & 55 & 78 & 20 & 72 & 20 & 30 & 30 & 42 & Full Fusion \\
\hline & 42 & 22 & 36 & 40 & 74 & 22 & 60 & 28 & 28 & 24 & 35 & Partial Fusion \\
\hline & 18 & 23 & 38 & 48 & 78 & 5 & 60 & 22 & 30 & 32 & 40 & Partial Fusion \\
\hline & 18 & 8 & 54 & 45 & 78 & 34 & 68 & 24 & 28 & 24 & 35 & Full Fusion \\
\hline & 30 & 26 & 42 & 43 & 60 & 18 & 60 & 10 & 30 & 20 & 43 & Partial Fusion \\
\hline & 22 & 10 & 28 & 42 & 68 & 32 & 70 & 18 & 28 & 18 & 33 & Partial Fusion \\
\hline & 56 & 9 & 28 & 44 & 60 & 20 & 50 & 5 & 25 & 18 & 28 & Full Fusion \\
\hline & 19 & 8 & 46 & 43 & 50 & 25 & 75 & 22 & 28 & 15 & 30 & Full Fusion \\
\hline & 24 & 9 & 35 & 39 & 60 & 15 & 65 & 15 & 33 & 26 & 45 & Full Fusion \\
\hline & 16 & 11 & 30 & 27 & 64 & 24 & 62 & 20 & 38 & 20 & 48 & Partial Fusion \\
\hline & 36 & 16 & 40 & 65 & 70 & 16 & 65 & 16 & 32 & 24 & 38 & Partial Fusion \\
\hline & 20 & 12 & 45 & 58 & 71 & 25 & 54 & 22 & 27 & 22 & 44 & Full Fusion \\
\hline & 42 & 9 & 46 & 47 & 72 & 13 & 65 & 10 & 38 & 25 & 42 & Full Fusion \\
\hline & 24 & 13 & 33 & 53 & 65 & 28 & 72 & 20 & 34 & 20 & 46 & Full Fusion \\
\hline & 40 & 25 & 33 & 45 & 73 & 15 & 56 & 20 & 24 & 22 & 50 & Partial Fusion \\
\hline & 20 & 20 & 35 & 45 & 58 & 23 & 52 & 19 & 36 & 23 & 40 & Partial Fusion \\
\hline
\end{tabular}




\section{Orthopedics and Rheumatology Open Access Journal (OROAJ)}

\begin{tabular}{|c|c|c|c|c|c|c|c|c|c|c|c|c|}
\hline & 24 & 9 & 51 & 48 & 60 & 18 & 68 & 16 & 30 & 26 & 46 & No Fusion \\
\hline & 24 & 25 & 47 & 42 & 70 & 26 & 64 & 19 & 32 & 24 & 42 & Partial Fusion \\
\hline & 27 & 14 & 31 & 48 & 65 & 20 & 53 & 13 & 33 & 18 & 48 & Partial Fusion \\
\hline & 51 & 8 & 32 & 49 & 65 & 22 & 58 & 18 & 30 & 19 & 46 & Full Fusion \\
\hline & 19 & 5 & 45 & 55 & 72 & 18 & 66 & 20 & 33 & 25 & 43 & Full Fusion \\
\hline Average & 28.2 & 13.5 & 38.6 & 46.3 & 67.8 & 19.5 & 63.5 & 17.5 & 30.1 & 23 & 42.2 & Full Fusion \\
\hline \multicolumn{6}{|c|}{$68.3 \%$} & \multicolumn{2}{|c|}{$30.7 \%$} & \multicolumn{2}{|c|}{$58.1 \%$} & \multicolumn{2}{|c|}{$54.5 \%$} & \\
\hline
\end{tabular}

\section{Discussion}

Despite the effective diagnostic and treatment options available today for detecting and treating scaphoid fractures, we continue to see a high number of scaphoid nonunion. Left untreated, scaphoid nonunion can progress to carpal arthrosis and scaphoid nonunion advanced collapse (SNAC). The distal part of the scaphoid will rotate into flexion while the lunate will assume an extended posture. Over time, this will progress into dorsal intercalated segment instability (DISI) and pancarpal arthrosis $[2,10]$. However, the radiolunate joint has consistently spared in SNAC pathway, even when there is severe DISI stance of the lunate. This preservation of the radiolunate joint is the basis of the 4-corner arthrodesis $[5,7,8]$.

Treatment of SNAC wrist has always been challenging. Different kinds of treatments, such as proximal row carpectomy, partial wrist arthrodesis, and total wrist arthrodesis have all been described with varying rates of success and complications [4,8,11-13]. Four corners arthrodesis together with bone grafting is a proven technique in the treatment of SNAC wrist with intact radiolunate articulation favored by many surgeons despite the variable tools used for fixation such as screws, k-wires, staples and more recently, the circular plates $[5,6,9]$. The circular plate combines the benefits of rigid internal fixation and hence early active ROM exercises with the ability to compress the four carpal bones together $[7,14]$. It is this feature that essentially makes it a potentially useful tool in the treatment of SNAC wrist.

We hypothesized that the circular plate would be an effective method for treatment of SNAC wrist. Twenty-four patients (92.3\%) in our series achieved full or partial solid fusion and reported a reasonable wrist range of motion as well as grip strength. Our study is limited by the lack of statistical analysis due to relatively low number of patients. Moreover, it is a small retrospective case series. Nonunion rates with conventional methods like K-wires, screws, or staples for fixation varies in literature between $0 \%$ and $18 \%[1,8,12,15,16]$. In other hand, nonunion rates with circular plates were reported between $0 \%$ and $63 \%[5,12,17]$, Bedford and Yang [6] and Merrell et al. [2] reported zero nonunion rate. The explanation for the varied results may be attributed to different tools that have been used, differences in quantity and quality of bone graft and exacting technique [6,9-11]. In our series we reported two cases of non-union (7.6\%). we attribute this to proper quantity and quality of bone graft, proper reaming and denuding of all cartilage surfaces, and rigid internal fixation afforded by circular plate. In two larger series of comparison studies, Ashmead et al. [6], and Watson et al. [13] reported $53 \%$ ROM of the opposite side. Our results fall near this range at $52.8 \%$ ROM of the opposite side. Our result of $34.9 \%$ grip strength of the opposite side lags behind those reported in the literature. Watson et al. [13] reported $80 \%$ grip strength of the opposite side and Krakauer et al. [9] reported $78.5 \%$ grip strength of the opposite side.

\section{Conclusion}

In our hands, use of circular plate for scaphoidectomy and four-corner arthrodesis was associated with good clinical and radiological outcomes. We believe that circular plate is a useful tool and is a good alternative to traditional implants like K-wires, Herbert screws, or staples.

\section{Conflict of Interest}

The authors declare that they have no conflict of interest.

\section{References}

1. T Trumble, C J Bour, R J Smith, G S Edwards (1988) Intercarpal arthrodesis for static and dynamic volar intercalated segment instability. J Hand Surg Am 13(3): 384-390.

2. Merrell GA, Mcdermott EM, Weiss AC (2008) Four-Corner Arthrodesis Using a Circular Plate and Distal Radius Bone Grafting: A Consecutive Case Series. J Hand Surg Am 33(5): 635-642.

3. Tomaino MM, Miller RJ, Cole I, Burton RI (1994) Scapholunate advanced collapse wrist: Proximal row carpectomy or limited wrist arthrodesis with scaphoid excision? The Journal of Hand Surgery 19(1): 134-142.

4. Bedford B, Yang SS (2009). High Fusion Rates with Circular Plate Fixation for Four-corner Arthrodesis of the Wrist. Clinical Orthopaedics and Related Research ${ }^{\circledR}$ 468(1): 163-168.

5. Luegmair M, Houvet P (2012) Erratum to: Effectiveness of FourCorner Arthrodesis with Use of a Locked Dorsal Circular Plate. Clinical Orthopaedics and Related Research ${ }^{\circledR}, 470(8)$ : 2332-2332.

6. Ashmead D, Watson HK, Damon C, Herber S, Paly W (1994) Scapholunate advanced collapse wrist salvage. J Hand Surg Am 19(5): 741-750.

7. Kendall CB, Brown TR, Millon SJ, Rudisill LE, Sanders JL, et al. (2005). Results of Four-Corner Arthrodesis Using Dorsal Circular Plate Fixation. J Hand Surg Am 30(5): 903-907.

8. Kijima Y, Viegas SF (2009) Wrist Anatomy and Biomechanics. The Journal of Hand Surgery,34(8), 1555-1563. 
9. Krakauer JD, Bishop AT, Cooney WP (1994) Surgical treatment of scapholunate advanced collapse. The J Hand Surg Am 19(5): 751-759.

10. Berger RA, Bishop AT, Bettinger PC (1995) New Dorsal Capsulotomy for the Surgical Exposure of the Wrist. Ann Plast Surg 35(1): 54-59.

11. Shindle MK, Burton KJ, Weiland AJ, Domb BG, Wolfe SW (2007) Complications of Circular Plate Fixation for Four-Corner Arthrodesis J Hand Surg Eur Vol 32(1): 50-53.

12. Wyrick JD, Stern PJ, Kiefhaber TR (1995) Motion-preserving procedures in the treatment of scapholunate advanced collapse wrist: Proximal row carpectomy versus four-corner arthrodesis. J Hand Surg Am 20(6): 965-970.

13. Rudnick B, Goljan P, Pruzansky JS, Bachour A, Jacoby SM, et al. (2014). Four-Corner Arthrodesis with a Radiolucent Locking Dorsal Circular Plate: Technique and Outcomes. Hand 9(3): 315-321.
14. Cohen MS, Kozin SH (2001) Degenerative arthritis of the wrist: Proximal row carpectomy versus scaphoid excision and four-corner arthrodesis. J Hand Surg Am 26(1): 94-104.

15. Klausmeyer M, Fernandez D (2012). Scaphocapitolunate Arthrodesis and Radial Styloidectomy: A Treatment Option for Posttraumatic Degenerative Wrist Disease. J Wrist Surg 1(2): 115-122.

16. Zimmermann MS, Weiss AC, Gotha H (2012) Failure of Proximal Row Carpectomy (PRC) and Four-corner Fusion (4CF) in Patients Younger than 50. The Journal of Hand Surgery 37(8): 31-32.

17. Bain GI, Watts AC (2010) The Outcome of Scaphoid Excision and FourCorner Arthrodesis for Advanced Carpal Collapse at a Minimum of Ten Years. J Hand Surg Am 35(5): 719-725.

\section{Your next submission with Juniper Publishers will reach you the below assets}

- Quality Editorial service

- Swift Peer Review

- Reprints availability

- E-prints Service

- Manuscript Podcast for convenient understanding

- Global attainment for your research

- Manuscript accessibility in different formats

( Pdf, E-pub, Full Text, Audio)

- Unceasing customer service

Track the below URL for one-step submission https://juniperpublishers.com/online-submission.php 